\title{
VATS lobectomy, history, indication, contraindication and general techniques
}

\author{
Hytych $\mathrm{V}^{1}$, Horazdovsky $\mathrm{P}^{1}$, Pohnan $\mathrm{R}^{1,2}$, Pracharova $\mathrm{S}^{1}$, Taskova $\mathrm{A}^{1}$, Konopa $\mathrm{Z}^{1}$, Cernovska $\mathrm{M}^{3}$, \\ Demes $\mathrm{R}^{1}$, Cermak $\mathrm{J}^{1}$, Vasakova $\mathrm{M}^{3}$, Benej $\mathrm{R}^{4}$
}

Department of Thoracic Surgery, Thomayer's Hospital, Prague, Czech Republic. vladislav.hytych@ftn.cz

\begin{abstract}
VATS lobectomy is a respected modality of anatomic lung resections nowadays. Video-assisted lobectomies without rib extractor fulfil all current requirements for minimally invasive lung resections. This type of an anatomic pulmonary resection with a targeted treatment of hilar structures doesn't traumatize the intercostal space by using rib retractor. Videothoracoscope serves to visualize the surgical field on the screen. Assisted VATS (aVATS) lobectomy is a procedure using $3-5 \mathrm{~cm}$ working incision. Fully endoscopic resection (VTS) or complete VATS lobectomy (cVATS) are operations performed only through ports, without working incision. The authors supplement the article with a videorecord of VATS lobectomy general technique (Fig. 4, Ref. 11). Text in PDF and video www.elis.sk.

KEY WORDS: video-assisted thoracoscopic surgery, VATS lobectomy, general technique.
\end{abstract}

\section{Introduction}

In 1585, Tulio Caesare Aranzi focused sunlight passing through the flask with water to the nasal cavity. He was the first person who used light source for endoscopic examination.

The founder of endoscopy is considered to be Phillip Bonzzini, who made the aluminium tube to visualize the urogenital tract in 1806. The tube was illuminated by candles and equipped with a mirror to reflect the image and light.

Antoine Jean Desormeaux used the Bozzini's "Leichtleiter" since 1853, in which he improved the light source. Thus, he is regarded as the father of endoscopy.

In 1901, Georg Kelling carried out the first experimental laparoscopy and thoracoscopy.

Sir Francis Richard Cruise performed the first thoracoscopy in humans in 1865 when he overlooked the pleural cavity of patient with pleurocutaneous fistula using the modified Desormeaux's endoscope.

Thoracoscopy and laparoscopy were established as the standard methods by Hans Christian Jacobabaeus in 1910.

Since 1991, when Giancarlo Roviaro performed the first VATS

\footnotetext{
${ }^{1}$ Department of Thoracic Surgery, Thomayer's Hospital, Prague, Czech Republic, ${ }^{2}$ Department of Surgery, Central Military Hospital - Faculty Military Hospital, Prague, Czech Republic, ${ }^{3}$ Department of Respiratory Medicine, Thomayer's Hospital, Prague, Czech Republic, and ${ }^{4}$ Department of Thoracic Surgery, University Hospital, Bratislava, Slovakia

Address for correspondence: $\mathrm{V}$. Hytych, MD, PhD, Department of Thoracic Surgery, Thomayer's Hospital, Videnska 800, CZ-140 59 Prague 4 - Krc, Czech Republic.

Phone: +420734767704
}

lobectomy in Milan, several techniques for mini-invasive lung resection have been described (1).

\section{Video-assisted minithoracotomy}

Minithoracotomy is 6-8 cm long and it is located in place of posterolateral thoracotomy under the angle of the scapula. Small rib retractor is used. Videothoracoscope is introduced through an auxilliary port above the diaphragm and it mainly serves to illuminate the surgical field. The surgical technique is not different from traditional open surgery (2).

\section{Video-assisted simultaneous stapled lobectomy}

The technique was described by Levis in 1999 (8). All hilar structures of the respective lobe are closed and at once interrupted by using the stapler. This operation can be performed without the use of rib retractor but from the point of oncological view, it cannot replace the standard lobectomy (2).

\section{Video-assisted lobectomy without rib retractor}

It meets all current criteria of mini-invasive lung resections. It is an anatomic pulmonary resection with a targeted treatment of hilar structures without the use of rib retractor. Videothoracoscope serves to visualize the surgical field on the screen. The operation, using $3-5 \mathrm{~cm}$ working incision, which is used for specimen retrieval at the end of the operation, and is called as assisted VATS (aVATS) lobectomy. If the operation is performed without a working incision and into the chest, we enter only through ports, we are talking about a fully en- 
doscopic resection or VATS, also a complete VATS lobectomy (cVATS) (3).

\section{The advantages of mini-invasive pulmonary resections}

Studies comparing open and mini-invasive surgery speak in favour of VATS resection (4):

- lower postoperative pain and the suppression of post-thoracotomy pain syndrome

- reduced time of drainage

- reduced time of hospitalization

- fast recovery

- lower complication rate

- better cosmetic effect

Mortality in both approaches is between $0-2.7 \%$ (4).

\section{The effect on suppression of the immune system}

Each surgical intervention is accompanied by changes in levels of hormones, cytokines and immunocompetent cells, which are a consequence of the stress response. It may result in increased risk of hematogenous dissemination of tumour cells and the formation of infectious complications (5).

- Interleukin-6 (IL-6) - high level represents a risk of infectious complications, tumour cell proliferation by growth factors (IGF),

- Interleukin-8 (IL-8) - is pro-inflammatory cytokine.

- In patients after VATS resections, lower pro-inflammatory interleukins and lower levels of CRP were measured. Low level of IL- 6 correlates with a smaller postoperative pain after the VATS resection.

- CD4 lymphocytes - have a central role in cellular immunity of the organism

- NK cells - have the cytotoxic potential, their activation is not required prior an encounter with a foreign antigen.

The group of patients after VATS resections had lower drop of the level of both groups of immunocompetent cells (6).

\section{Reduction of postoperative pain}

Postoperative pain is undesirable but it is an integral part of every surgery. Its treatment plays an essential role in the postoperative period. After a pulmonary resection, an early mobilization, re-expansion of the operated lung and rehabilitation are very important (4). - Myofascial component - as the result of surgical approach: transection and subsequent muscle suture, retraction of the ribs, subluxation of costovertebral connections, rib fractures or controlled interruption of ribs. Mini-invasive operations minimize the occurrence of this component of postoperative pain.

- Neuropathic pain - is caused by the intercostal nerve damage. Neither VATS surgery using hard ports nor drains with an excessive diameter can exclude the intercostal nerve injury.

\section{The effect on pulmonary function}

Each lung surgery leads to:

- loss of parenchyma,
- trauma of the chest wall and respiratory muscles.

Mini-invasive approach results in rapid normalization of vital capacity (VC), forced expiratory volume in 1 second (FEV1), blood gases and respiratory muscle repair (7).

\section{Method ERAS in thoracic surgery}

Since the 90s of the last century, a multimodal access to elective operations has been developing. It was summarized by Kehlet in the so-called ,enhanced recovery after surgery" (ERAS) or ,fast track“.

- complete examination

- determining the scope and method of operation

- personal access of a surgeon with a detailed description of the techniques, tactics, results and complications.

- psychological preparation, obtaining of confidence, improve of psychosomatic condition

- optimization of internal environment before operation

- gently guided anaesthesia using epidural and subarachnoid anaesthesia and ongoing analgesia

- physiological surgical technique using mini-invasive procedures

- after surgery: pain control, reduction of post-operative complications, stabilization of internal environment, an early normalization of peristaltics, mobilization and respiratory rehabilitation (6).

\section{The selection of suitable patients for VATS lobectomy}

- staging of malignant disease

- mediastinal lymph nodes

- size and localization of pulmonary lesions

- preoperative internal, pneumological and cardiological examination

- age is not a limiting factor

\section{Indications for VATS lobectomy}

- benign disease requiring implementation of anatomical resection

- malignant disease with tumour size $<6 \mathrm{~cm}$

- localization in the periphery or $>1 \mathrm{~cm}$ from a fissure or $>3 \mathrm{~cm}$ from the lobar carina

- TNM stage I or II

- N2 lymph nodules uninvolved by metastases (detected peroperatively are not a contraindication to VATS lobectomy)

- solitary metastasis of extrapulmonary cancer, which cannot be removed with a typical wedge resection

\section{Contraindications of mini-invasive lung resections}

Absolute:
- inability of selective ventilation (one lung ventilation)
- obliteration of the pleural cavity
- extensive growth
- N2 disease
Relative:
- previous thoracic surgery




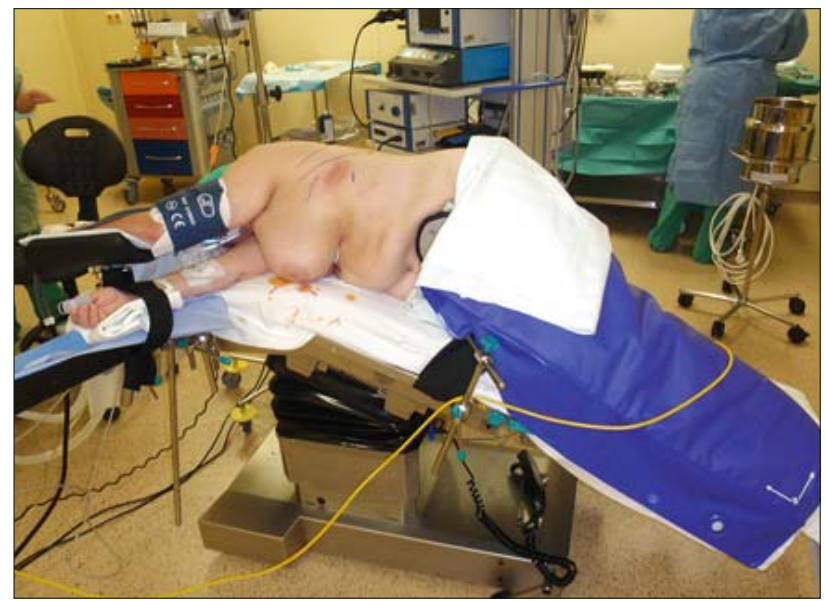

Fig. 1. VATS lobectomy - patient position.

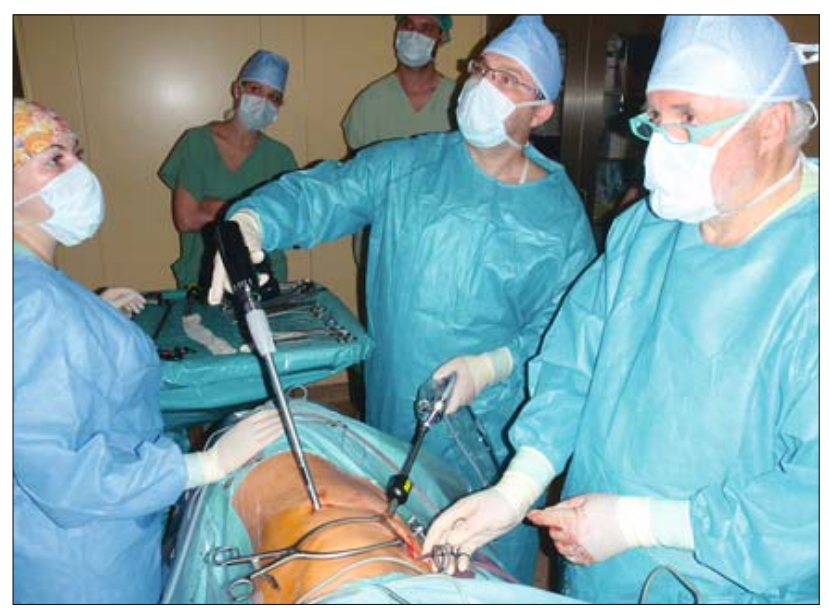

Fig. 2. Left upper VATS lobectomy - operation team position.

- extensive pleural adhesions

- previous chemoradiotherapy for lung cancer

- enlarged lymph nodes N1

- defunct fissures between the lobes

\section{The technique of hilar structures and lung parenchyma treat- ment}

The basic step for the anatomic lung resection is the identification, preparation, closure and interruption of hilar structures of the resected lung lobe. The emphasis is on the reliability of treatment. A failure of vascular closure has resulted in a massive postoperative bleeding with possible fatal consequences and a bronchial stump leak enforces operational review. Mini-invasive lung resections compared to conventional operations provide a number of differences in surgical technique (9).

Currently, the front approach is used in VATS lobectomy (Fig. 1). The surgeon and assistant stand in front of the patient who is lying on his healthy side, the surgeon is closer to the head of the patient and scrub nurse stands against the surgeon (Fig. 2). The operating table is "broken" and videothoracoscopic tower is behind

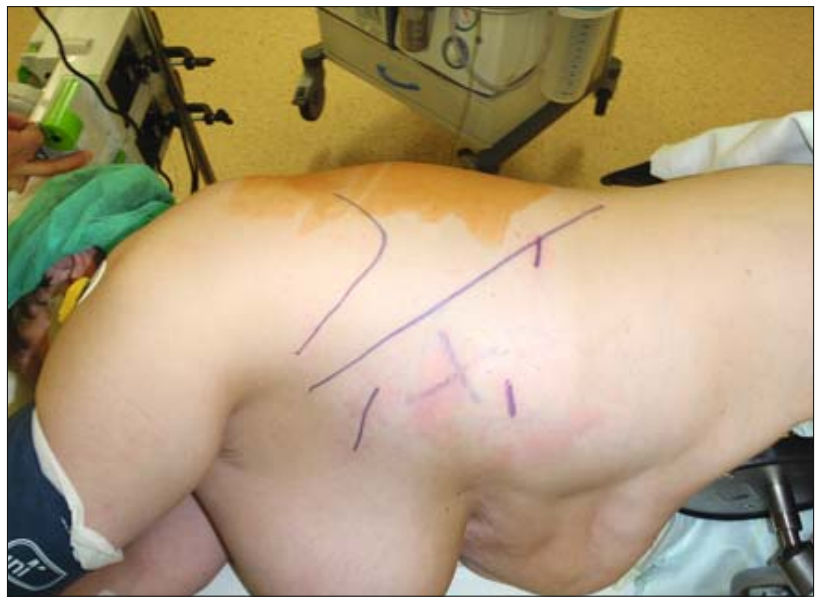

Fig. 3. Left upper VATS lobectomy - incision position.

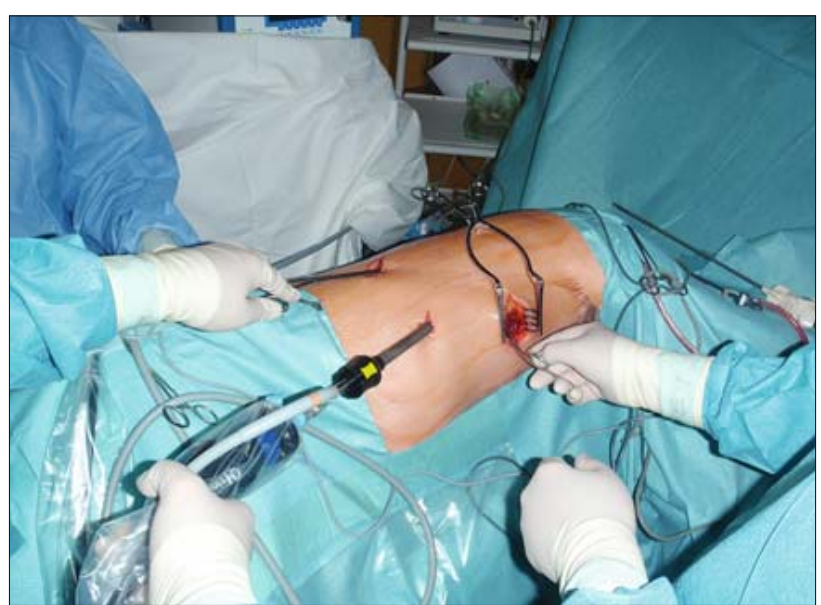

Fig. 4. Right lower VATS lobectomy - utility incision, camera and working incision.

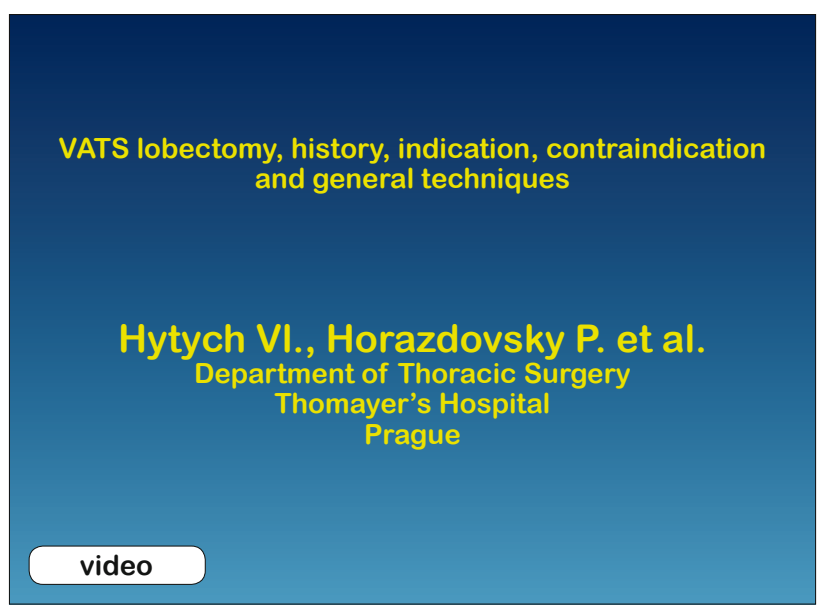

the patient. Satellite monitor is above the patient's head for a good overview of assistant and nurse. To enter the chest, three incisions are made. Minithoracotomy is located in the middle third of the line between the lower angle of the scapula and nipple. Under a visual control, the camera input is placed at the level of the top of 
the diaphragm in the anterior axillary line and kept in the line of front border of the pulmonary hilum. The labor input is placed at the same height in the back axillary or scapular line (Figs 3 and 4).

A detailed magnified view into the pulmonary hilum through videothoracoscope allows to move from the periphery to the centre of the hilum. Structures are treated sequentially from the pulmonary vein to lobar bronchus. The last interlobar fissure is split and the lobe is taken out through minithoracotomy.

The most commonly used technique for the treatment of pulmonary vessels and bronchi are staplers designed for minimally invasive surgery (endostaplers). Their advantage is a speed and the reliability of suture. Its disadvantage is the use of solid tool for segmental branches of the pulmonary artery because microcracks with blood leaking can occur when vascular wall is gracile. Stapled bronchial treatment is quick and safe. It is necessary for the perfect visualization and control of the level of the resection line. The interlobar fissure can be separated by blunt dissection using two small tampons, harmonic scalpel, mono or bipolar electrocoagulation or staplers at the end of resection after an interruption of hilar structures (10).

Alternative to stapler in the treatment of pulmonary hilar vascular structures is the use of clips. It is a small plastic or metal clips in the form of horseshoe having the free ends lockable. After placement and constriction with the applicator, the hangers of horseshoe close the vessels and the clip is secured with a lock. Vascular locking clips are an invaluable tool for the treatment of small vessels (11).

Hilar structures may be treated with ligation of vessels or manual suture of the bronchial stump. It depends only on manual skills, erudition, courage and experience of the surgeon.

\section{Conclusion}

In case of selected and indicated patients, VATS lobectomies are alternative of open lung resections. In favour of VATS resection testify a lower postoperative pain and the suppression of postthoracotomy pain syndrome, reduced time of drainage, reduced time of hospitalization, faster recovery, lower complication rate and better cosmetic effect.

It can be assumed that VATS lobectomies become the method of choice for indicated patients and the method will widespread in clinical practice.

\section{References}

1. Smythe W, Kaiser LR. History of thoracoscopic Sumery. In: Kaiser LR, Daniel TM (Eds). Thoracoscopic Surgery. Little Brown and company, 1993, 273.

2. Horažd'ovský P, Hytych V, Hromádka P. Chirurgická léčba neuroendokrinních nádorů. In: Neuroendokrinní nádory plic a mediastina. Praha: Maxdorf, 2014.

3. Benej R, Janík M. Endoskopické anatomické resekcie plúc. In: Benej $\mathrm{R}$, Haruštiak $\mathrm{S}$ et al. Súčasná video-asistovaná chirurgia hrudníka. Turany: $\mathrm{P}+\mathrm{M}, 2013$.

4. Inderbitzi R, Schmid R, Melfi F et al. Minimally Invasive Thoracic and Cardial Surgery. Springer, 2012.

5. Yim AP, WAN S, Lee TW, ARIFI AA. VATS lobectomy reduces cytokineresponses compared withconventional Sumery. Ann Thorac Surg 70; 2000: 243-247.

6. McKenna RJ, Mahtabifard A, Swanson SJ. Atlas of Minimally Invasive Thoracic Sugery (VATS). Elsevier Saunders, 2011.

7. Nakata M, Saeki H, Yokoyama $\mathbf{N}$ et al. Pulmonary function after lobectomy: video-assisted thoracic Sumery versusthoracotomy. Surg Today 33; 2003: 7-12.

8. McKenna RJ, Mahtabifard A, Pickens A, Kusuanco D, Fuller CB. FastTracking After Video-Assisted Thoracoscopis Surgery Lobectomy, Segmentectomy and Pneumonectomy. Ann Thorac Surg 84; 2007: 1663-1668.

9. Gossot D. Atlas of Endoscopic Major Pulmonary Resections. Spinger Verlag France 2010.

10. Hansen HJ, Petersen RH. Video-assisted thoracoscopic lobectomy using a standardized three-port anterior approach - The Copenhagen experience. Ann Cardiothorac Surg 2012: 1, 70-76.

11. Zwischenberger JB. Atlas of Thoracic Surgical Techniques. Saunders Elsevier, 2010. 